\title{
Spatial primitives and knowledge organization in planning and architecture: some experimental notes
}

\author{
Dino Borri, Domenico Camarda* and Rossella Stufano
}

\begin{abstract}
Cities and territories share structural references to a common environmental ontology, in which space perception and representation play a major role. Many human abilities deal with space management, whose ontology can be useful in building intelligent machines in which space conceptualization plays a fundamental role. Space organizing is an important human ability, in which sensorial and mental abilities intriguingly interact. The analysis of human intelligent abilities in this functional perspective helps in shedding light on aspects otherwise erroneously given for granted. Human agents conceptualize, design and organize spaces for human organizations, for example in architectural design, by using numerous routine and non-routine cognitive processes often analysed. Yet automated reasoning/ design agents still provide only bad copies of human performances. Here, creativity is postulated as a non-routine sophisticated human cognitive function, a conscious and intentional process for redefining agents' situations in the world in new ways. Even if the concept of creativity remains controversial, an increasing number of cognitive scientists considers creativity as a specific part of the ordinary cognitive equipment of the human agent, to be used in certain situations, not confined to a limited set of exceptional human agents .In this context, we assume that it is worthwhile adding spatial domain to the other domains of creativity studied in cognitive science. We also assume that space understanding and space organizing can be fruitfully analyzed and modelled by paying attention to both routine and non-routine (creative) cognitive functions. The domain of civil architecture is a relevant domain of spatial knowledge and action and of course of spatial organization. In it, aesthetics and art, based on creativity mechanisms, play an important role. Studies on architectural creativity based on self-biographies by leading architects (who usually motivate their designs with memories of other designs or spaces, or architectures, experienced by them in the past) prove that spatial memory has primary importance on creativity.

The paper carries out an introductory discussion on such issues, by analysing the case studies of single-agent and multi-agent spatial organizations under the level of spatial design. The paper explores possible modelling approaches and system architectures supporting cognition-oriented activities in spatial organizations.
\end{abstract}

Keywords: Spatial memory; Spatial creativity; Multi agent planning; Urban architecture; Spatial organizations

\section{Introduction}

Cities and territories share a structural reference to common root concepts and ontologies. One of the very last quintessential concept is the environment, profoundly reshaped and redrawn during the last few decades. Due to such a harsh reshaping process, an new issue of complexity has increasingly emerged to show the importance of hidden, uncommon, fuzzy linkages among

* Correspondence: d.camarda@poliba.it

Technical University of Bari, Via Orabona 4, 70125 Bari, Italy environmental entities and processes toward the configuration of the environment as an actual system (Sawyer 2005; Bossomaier and Green 2000). Today, we commonly deal with the environment with reference to either natural or artificial contexts, cities and external territories (cities with external territories), etc., as parts and features of a unique complex system.

The concept of space is central in the ontological structure of the environment as a complex system, particularly when dealing with actors of the societies living in environmental systems. The perception and the complex

\section{黛 Springer}

(c) 2014 Borri et al.; licensee Springer. This is an open access article distributed under the terms of the Creative Commons Attribution License (http://creativecommons.org/licenses/by/4.0), which permits unrestricted use, distribution, and reproduction in any medium, provided the original work is properly credited. 
representation of the environment and the evolution of environment-based socialization have become critical issues, that have been explored particularly by social science over the last decades (e.g., Sandercock 1998). Also, the inclusive conceptualization of space representation and management represents a critical step toward the building up of intelligent machines based of ontological space description. Furthermore, space organization is an essential share of the spatial abilities of human agents, made up of intriguing sensorial and cognitive interplays.

In this context, a deeper functional analysis of the intelligent abilities of human agents is worthwhile doing, so as to shed light on spatial features, and avoid accepting superficial explanations. As a matter of fact, human agents are able to first conceptualize spaces, then design and organize them for human organizations. For example, they can apply such features in architectural design, by making use of intriguing cognitive processes based on routinary as well as non-routinary approaches that need to be investigated (Schön 1983). Basically, this is another case in which the evolution of techniques and technology on automated reasoning and automated design agents, from origins to current high-level status, could not provide but flawed duplicates of human abilities (Hofstadter 1995).

If we consider the concept of creativity, we find it is assumed as a complex non-routinary cognitive feature of human agents, that is, an intentional and intrinsically aware process used by agents' cognition to redefine in new ways her/his situations within the world. Although creativity does remain debated concept, some literature increasingly tends not to consider it as a prerogative of few special human agents. Rather, creativity is more and more seen as a particular portion of the normal cognitive patrimony of the human agent, apt to be used in specific circumstances (Weisberg 1993; Bink and Marsh 2000).

This research tries to add space domain to other typical creativity domains examined in cognitive science. In particular, the concepts of space understanding and space organizing are scanned by making reference to creative (non-routinary) cognitive functions, beyond the routinary ones, in a modelling perspective. In this context, we have explored suggesting case-studies of interactive creative actions among civil architects, within a game-theory framing situation (space organization) (McCain 2010).

The knowledge about space, spatial action and organization of space contribute significantly to build the domain of civil architecture. Within such concurring participation, a critical role is played by disciplines as aesthetics and art, that are intertwined with the mechanisms of creativity. In particular, some studies deal with architectural creativity, as investigated through self-biographies by master architects. Basically they represent the architects' memories of designs, spaces, architectures, experienced along their life and reported as commented memos for new design activities. Such literature is able to suggest that space memory strongly and primarily affects work approaches and creativity (Zumthor 1998). Also, because architecture is made up of technology, too, then spatial memories are suitable to be scanned through the concept of technological memory. This is an emerging topic, that is increasingly considered as useful to conceptualize technological change in its interplay between tradition and innovation (Borri et al. 2010).

Experimental sessions carried out here are mainly interactions that simulate a cooperative activity. They are actually based on a chess-type interaction game among architectural design agents, whose only goal is playing per se. Architects' graphic design moves on a paper sheet are recorded on a multimedia environment and then analyzed by researchers. Then ontologies and procedures are extracted and discussed from snapshots à la Veloso (Aboutalib and Veloso 2007). Analyses suggest that creativity is highly tributary to memories, coming from both expert, domain specific knowledge and nonspecific knowledge (Hofstadter 1995). Routinary moves (reactiveadaptive routines) seem to depend on the restrictions placed by other characters of the space that is being designed. On the contrary, non routine (creative) moves are apparently depending on the memories and the abilities that the expert agent succeeds in activating during her/his designing tasks. Interestingly, the incoming of further agents in the interaction arena drives to the establishment of a coral dialectic with the two original agents, like in an orchestra concert. This circumstance is interestingly similar to the creative no-goal jazz session with suggested by Schon to explain cooperative planning actions (Schön 1983).

The basic framework of the present paper, that draws out some introductory notes from the experimental sessions carried out, can be described as follows. After the present introduction, the next section deals with some preliminary problems in strategic planning, particularly addressing the active vs. reactive modes of planning. Section Analyzing and modeling spatial creativity analyses the intriguing interplays between memory end creativity in cooperative/competitive design plans by civil architects, using some suggesting case studies. Brief discussion and conclusions are carried out in Section Concluding Discussions and follow up.

\section{Cooperation, determinism, reactivity dilemmas in strategic planning}

Nowadays, strategic planning is considered an attractive type of spatial planning, because it allows more democratic as well as visionary, perspective features. Yet, tough difficulties emerge in both logical and computational terms when considering the multiagent aspects of spatial planning (Jennings and Wooldridge 1998). In particular, this difficulty poses a problem on the frequent process of synthesizing single individual choices from social choices. 
As Arrows puts down, such intriguing problem is rather irresolvable without relaxing the conventional rationality axioms (Arrow 1963).

Yet, although the operation of relaxing rational axioms is classically hard, new approaches seem to be promising. In particular, the last decades have given birth to new forms of interactive planning, involving even large numbers of agents in complex social and technical tasks. In such cases there is typically a tough dilemma between cooperation and non-cooperation or competition among agents, subdivided in a great range of possible fuzzy and at times undefined actions and conflicts, urging robust scientific reflections.

Theoretical as well as historical models of spatial planning seem to show that an abstract-procedural-normative (APN) model of planning, born in systems theory and in cybernetics, has found few applications in spatial planning. This rational approach has been even hardly discussed and evaluated in domain literature. On the contrary, it is still prominent in optimization-based management science and computer science. APN model proves to be competitive when dealing with the optimization of an individual's perspective (Borri et al. 2005).

Another rational model of planning (practical-procedural-non-normative, PPNN), born in communicative and organizational theories and inspired by behavioural paradigms of social interaction, needs to be considered. Although largely used in spatial planning, it is rejected by formal optimization planning because the complexity of routines hampers the setting up of a functional and logical architecture. PPNN model has gradually grown from involving small to large group (Lewin 1948), toward a context more typical of comprehensive urban/regional planning. As it is based on agents' interactions, PPNN model shows a marked cooperative feature.

However, APN as well as PPNN models make use of systems theory/analysis to provide own routines with a number of distinctive systemic prerogatives. On the one side, APN uses systemic processes to give rational direction in complex processes. On the other side, PPNN provides stronger resilience to systems based on manifold mechanisms and agents. Both fall short in situations of many variables and agents, as well as of semantic complexity, such as ambiguity and uncertainty. In fact, in these cases a proper explorative, creative and not procedural rationality is demanded. To this aim, hybrid approaches are more useful, able to put an APN procedure as individuals in PPNN procedures, or to insert a logical procedure based on a social responsibility of the individual agent in APN procedures (Barbanente et al. 2001).

If knowledge on an initial state is fully available, then a plan can be classically defined as "a sequence of actions that leads the agent from the initial situation to a goal state". Yet, if initial knowledge is incomplete (as normally occurring in spatial planning), then manifold action sequences can develop from different potential starting situations (Baral et al. 2000, pp. 241-242). Today, conventional planning approaches diffusely considers such classical planning as not being quite useful in real world situations. Conversely, it does remain valuable in many sectors, ranging from logistic to process planning and programming (Giunchiglia and Spalazzi 1999). In addition, classical planning has been recently enhanced on its intelligence and operability, as in case-based planning (Hammond 1990), multi-agent planning (Jennings and Wooldridge 1998), and non-STRIPS planning (the acronym stands for Stanford Research Institute Problem Solver (Blum and Furst 1997; Fikes and Nilsson 1971)).

In a more specific way, generating a plan may involve basically two aims, i.e., the reaching of a goal or the reaction to an external occurrence. In general, a goal is a condition related to intermediate as well as final action states: yet, classic planning normally considers a goal as a condition put down on a final state, formally expressed as a "conjunction of clauses" (Chang and Char-Tung Lee 1973, p.48; Agre and Chapman 1988; Fikes and Nilsson 1971).

A classic planning approach typically assumes that the initial, state as well as all the effects of actions, are known and that the world is substantially unchanging, close and static. It results that classic planning is inapplicable to such dynamic and unpredictable domains as social and environmental domains (but even to robotics or to the navigation of networks). Intelligent classic planning can be efficient (i. e., correctly functioning) but still ineffective if it falls short in reaching its goal (Giunchiglia and Spalazzi 1999, p.330).

We will now look at the economic standpoint. The theory of rational choice assumes that in order to reach a goal, an agent needs to scrutinize and evaluate available alternative actions against possible outcomes and a related utility function. Practical situations are intractable by this theory because they result as very complex (Horty and Pollack 2001). Planners that make use of abstractions, or hierarchies of tasks, or other heuristic-based mechanisms to scan and drive solutions through potentially infinite spaces are more able to deal with real-world problems (Bacchus and Kabanza 2000).

Planners involved in HTN (Hierarchical Task Network), for example, use domain knowledge under the form of a scheme of task decomposition. In comparison to classic planners, HTNPs require large domain information, together with task sets and decompositions of tasks. The architecture of HTN plans allow getting around large regions of the space of searching, so restricting the exploration only to primitive actions that result from selected sequences of the decomposition of tasks. In the end, HTN planners use parsing algorithms to prune plans that are partially ordered basing on primitive actions. 
There are theoretical and practical experimentation showing the existence of metastrategies that can be applied in diverse domains, with little adaptation (Bacchus and Kabanza 2000; Bauer et al. 1991; Rosenschein 1981). In our socio-environmental domain, that is a real-world domain, planners search only on portions of alternative spaces of action, so avoiding an infinite domain. Particularly resource limitations (such as time) drive their exploration of action potentials of actions, often making use of an instinctive automatism that planners' memory unconsciously selects among all possible automatisms for a given planner in a given plan. Such occurrences show that the searching space is not characterized by a feature of infinity -then resulting only an abstraction. Infinity does not exist in the restricted context of practical reality, and this is a stimulus toward theoretical reflections that address the modalities through which operational searching spaces are formed and become functional (Bauer et al. 1991).

Supposing a given system as described by a number of constraints and state features, it is interesting to reflect on the modalities of integrating the effects of an agent's action in the world (action of the first order), with the impact of the system's actions (of the second order) on the agent her/himself and her/his ability to perform that action. This involves reflecting on 'structure' problems (McCarthy et al. 1969), 'ramification' problems (Finger 1986), and 'qualification' problems (McCarthy 1977), that are largely debated but never actually solved problems (McIlraith 2000). When an action needs is represented by state constraints, a couple of aspects emerges as significant roles played. First, constraints encapsulate the relationship between existent objects and coherent states of the system. Second, they work as ramification as well as qualification constraints, and in this way they define intrinsically the indirect effects of actions, so constraining the implementation of further actions.

There are alternatives to classical planning, one of which has been recently proposed in terms of reactive planning (Simon 1982). Basing on the stimulus-and-response principle, it has developed mainly in rapidly changing domains, and the so-called 'universal plan' is probably the most renowned case (Schoppers 1987). A universal plan is a function that implies levels of decisions at any step of a process, about the modalities of making the following step basing on the current state at the time of decision. This is different from generating a process of actions from an initial toward a final state, i.e., from the classical planning approach. Although universal plans would inherently involve exploring enormous spaces (Ginsberg 1989b; Ginsberg 1989a), general planning problems (with the exception of socio-environmental ones) show a degree of structuring apt to generate universal plans that are small and effective (Schoppers 1987), even in an oversimplification (contested in literature) of the inherent polynomial hierarchy (Selman 1994) (Papadimitriou 1994).

Aiming at narrowing the concept and scope of universal plans, some scholars propose the limitation of universality by using few properties, such as plan solidity and in plan completeness (Jonsson et al. 2000). Also, in order to enhance the operability performances of universal plans, probability features are explored. In fact, universal plans are connected with casual databases that allow a coherent redefinition of completeness so as to include the case. An example of such probabilistic and reactive universal planner is Stocplan (Jonsson et al. 2000). However, the stratagem is not enough to relieve universal plans' inefficiency when facing general-plan problems, so basically narrowing their applicability to limited problem classes.

In fact, when comparing Stocplan with other classical planners in a number of testing domains (e.g., the traditional toy blocks world or other frameworks), there are not particular differences in results, so meaning that shortfalls still remain unaddressed (Blum and Furst 1997; Jonsson et al. 2000).

When turning to socio-environmental plans, both classical and reactive planning approaches show even more criticalities and inefficient performances, so involving an enlargement of reflection categories, in order to achieve more substantial effectiveness. Spatial issues become an essential parts of the planning domain, with typical but also novel senses induced by the complex-systems approach. In particular, spatial cognition aspects become highly significant in characterizing the domain relevant to the planning effort. Cognitive features such as perception, representation, organization of spaces add to Euclidean features to build up richer and augmented knowledge bases to which planning agents and models need to refer more structurally, with particular attention to knowledge managing prerogatives and abilities.

\section{Analyzing and modeling spatial creativity General issues}

In common and commonsense discussions, creativity is considered as an innate ability, by which actions of original creation give rise to brand new items and elements. On the other side, creativity can be also regarded as a process able to transform and recombine existing entities, toward different, novel configurations.

The field of architectural composition indicates that creativity is an original starting point for a process of transformation that follows a quasi-musical sequence. It is a peculiar attitude addressed at transforming the reality in an unconventional way, which is represented as a memory. This attitude is largely dependent on environments, architects, lifestyles. As a matter of facts, spatial creativity 
is a terrain on which it is hard to fix an objective, a referential framework for the interpretation of artistic and/or architectural creations. It drives to an intertwining of own memories, reminiscences with the resemblances of different artists and/or architects.

Particularly, the following exploration focuses on the singling out, manipulation and storing of memories in form of concrete images but also of spatial schemes and patterns, acting as spatial references for drawing on a blank space. This blank space is a paper sheet ready to be made 'dirty' by the agents' putting shapes, geometries or constraints, in a physical but also mental action, so as to develop the proper drawing effort.

Therefore, the present chapter shows two design approaches, apparently very different from each other, involving multiple agents or a single agent in the carrying out of given design tasks. A brief discussion will follow to evaluate contextual results. All the experimental sessions are organized by (and some actually held in) the AAM art Gallery in Rome.

\section{Duels vs. duets on a blank sheet}

The first experimenting framework presents a layout situation made up of two expert agents approaching the blank sheet together. Clearly, this is not a case of solving design problem: rather, it is just starting up and sharing a drawing game from scratch. In the entire series of meetings, the basic layout situation is made up of pencil duels/duets among architects. Because of this reason, the meeting series in the gallery is titled 'Chess games', emphasizing the seemingly 'gaming' process occurred in the drawing space, where master protagonists of contemporary architecture play together.

In this context, 'chess games' show intriguing and suggesting interaction dynamics. In particular, the mutual positions of objects and agents evolve according to agents' cognitive actions developed in the spatial contexts. Such moves and cognitive actions drive to step-by-step, evolutionary results, coming out from the efforts on the drawing space.

All sessions set up in the gallery are all documented by multimedia files. They are carried out with a multi-agent layout, in which dr. Vincenzo d'Alba, a young Italian architect and design virtuoso, is present in all sessions. The objective of meetings is not to share a project, but rather an experience, a space of design, in order to organize and sign it, starting from scratch. Therefore, we can say that the layout shows up as being objectiveoriented, rather than dialogue-oriented.

Material resulting from the sessions is interesting, particularly with regard to some fundamental questions, such as the behaviour of an expert agent in a multiple-agent 'paper space'. In Figure 1 there is a visual excerpt of the first interaction carried out with Alvaro Siza.

The observation of the expert agent shows how spatial memories are connected to his own formative history. When reference memory is richer, then drawn images are more numerous and significant. But memories are stimulated also from the interaction: therefore, new images of old memories are created, as well as new memories can revive old images, following a permanent and repeated intersection of cognitions and actions.

Furthermore, the process shows some evident themes and features of creativity. First, the role of the environment is critical and represented by context-based constraints on memories, as well as on novel associations of primitive forms or derived forms of geometry. It comes out also that creativity is not a rational process in a pure form, but it is strictly combined with the concept of intentionality in actions. The intention of drawing an image, perhaps aimed at an architectural creation, stimulates creativity and boosts the image drawing itself. From the cognitive point of view, the task of image drawing is similar to move a computer cursor in the brain, soliciting our attention focus: more than paper design, it is actually 'mental design' (Kosslyn 1996; Baddeley 1997; Shepard 1978).

Mental representations, objects that are in multiple places of memory, and that create the referential bulk of the expert agent, represent an actual database which is in permanent evolution. In it, diverse themes and memories that are distant in space and time become essential portions of its cognition structure (Arielli 2003).

Architect Zumthor puts down that the valuable moments of the inspiration of the expert agent come out from a patient work, following and developing an abrupt appearance of an internal image concerning the realization of a new design piece, by which the entire project structure changes and is reorganized in few seconds (Zumthor 1998). A synthetic table of the main process features of some of the most intriguing duet/duel sessions is represented in Figure 2.

Interactions appear as cooperative games, even with different relevance. However, this is not an exclusive peculiarity, since at least session n.4 shows a completely uncooperative approach. In this case, the behaviour of agents with each other starts with indifference and leads to a rather null interaction. As a whole, cooperation seems to be most fruitfully oriented to consistent and consequent drawings when cooperation is well ensured. It is interesting to note that the high number of agents involved is not an obvious guarantee either for cooperation and proactive behaviour, or for consistent drawings. Session n.1 confirms this occurrence with only 2 agents.

In general, that session is thoroughly very instructive. By examining video clips, we realize that first expert's work develops in an intricate and intriguing interweaving with her/his memory and with the memory of the second expert. Architects look mutually at their drawing advancements and complete the creative spatial work when one of them stops. Then they resume and organize their process again. It seems evident how cooperation revives autochthonous memories and stimulates new elaborations and associations, in an evolutionarily creative path. 


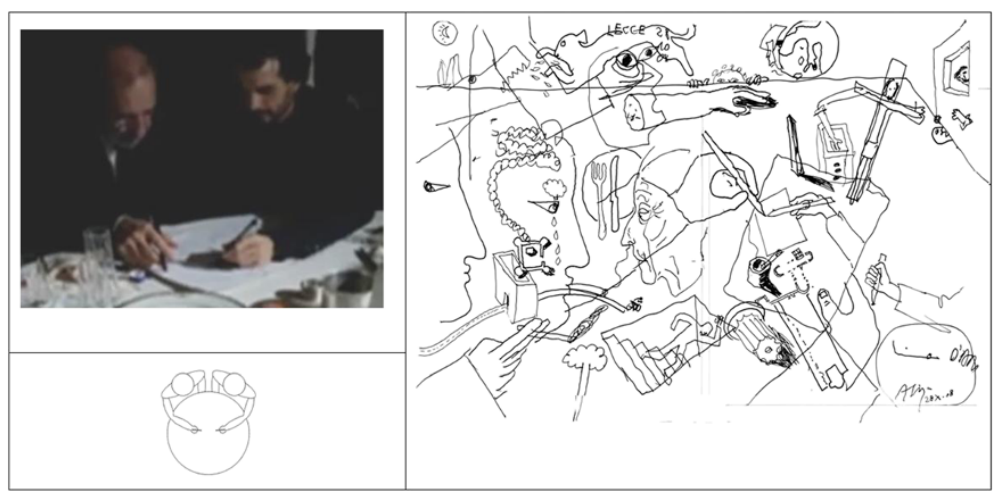

Figure 1 Agents interaction, their position at the table and the output drawing.

\section{Solo performances}

Chess games were designed with the purpose of creating a framework where to share form and architectural creativity, a design space to be organized through a multiagent approach, starting from a provocative initial point in game mode.

Now we try to investigate issues with a more direct single-agent approach. We refer to the methodological framework proposed by Buchanan at the end of the 1980s for the elicitation of expert knowledge in the field of artificial intelligence through 'sharing observation' (Forsythe and Buchanan 1989; Schön 1983). It is a silent observation, a light interference by the knowledge engineer, toward the expert involved in the execution of the analysed task. The architect was observed while working alone this time, facing a blank sheet of paper, with a design theme that is unknown until the beginning of the experimental design.

The purpose of the experiment is to try to understand what are the geometries and the reference memories of a project work. The theme that has been put forward to the architect is the design of an urban door. The sequence of sessions observed was reported on video clips and can be listed as follows (Figure 3 and Figure 4):

1. First extemporary drawings

2. Development of what had been drawn in the previous meeting, toward the definition of the leading project idea

3. The leading project idea comes to maturity and reaches a detailed definition with own themes, materials, languages, shapes

4. The designer looks at the city and the environment surrounding the door

5. The designer shows possible types of urban doors among which to choose

6. Conclusion and definition of the door

Between those drawing meetings, interval interviews are carried out, where the designer deals with his signs, explains the reasons behind his choices, describes the mental path underlying the unraveling of materials and drawing objects.

\begin{tabular}{|c|c|c|c|c|c|c|c|c|c|c|c|c|c|}
\hline & agents & environment & table & sheet & $\begin{array}{l}\text { agents' } \\
\text { position }\end{array}$ & $\begin{array}{c}\text { agents' } \\
\text { working } \\
\text { sequence }\end{array}$ & $\begin{array}{c}\text { initial } \\
\text { interaction } \\
\text { behaviour }\end{array}$ & \begin{tabular}{|c|} 
standard \\
interaction \\
behaviour \\
\end{tabular} & $\begin{array}{c}\text { drawing } \\
\text { space } \\
(\% \text { sheet) }\end{array}$ & $\begin{array}{c}\text { sequence of } \\
\text { agents' } \\
\text { drawings } \\
\end{array}$ & $\begin{array}{c}\text { drawing } \\
\text { consistency }\end{array}$ & $\begin{array}{c}\text { game } \\
\text { appearance }\end{array}$ & $\begin{array}{c}\text { most } \\
\text { committed } \\
\text { agent }\end{array}$ \\
\hline 1 & $\begin{array}{l}1 \text { (Siza) } \\
2 \text { (D'Alba) }\end{array}$ & $\begin{array}{l}\text { crovded, } \\
\text { moder.noisy, } \\
\text { music }\end{array}$ & round & large & $\begin{array}{l}\text { side by } \\
\text { side }\end{array}$ & $\begin{array}{l}2 \rightarrow 1-\overrightarrow{2} \\
1 / 2-2\end{array}$ & $\begin{array}{l}\text { attentive, } \\
\text { ready }\end{array}$ & $\begin{array}{c}\text { strongly } \\
\text { proactive, } \\
\text { reactive }\end{array}$ & $100 \%$ & $\begin{array}{c}\text { mostly } \\
\text { continuative }\end{array}$ & $\begin{array}{l}\text { mostly } \\
\text { coherent }\end{array}$ & cooperative & 2 \\
\hline 2 & $\begin{array}{l}1 \text { (Purini) } \\
2 \text { (D'Alba) } \\
3 \text { (Ortiz) } \\
4 \text { (external) } \\
5 \text { (external) }\end{array}$ & crowded, noisy & rectangular & $\begin{array}{l}\text { narrow, } \\
\text { long }\end{array}$ & $\begin{array}{l}\text { side by } \\
\text { side }\end{array}$ & $\begin{array}{c}2 \rightarrow 3 \rightarrow 1 \\
\rightarrow 1 / 2 \rightarrow 2 \\
\rightarrow 1 \rightarrow 1 / 2 \\
\rightarrow 1 / 2 / 3 \rightarrow \\
1 / 4 \rightarrow 1 \rightarrow \\
1 / 2 \rightarrow 3 \rightarrow \\
5 \rightarrow 3\end{array}$ & $\begin{array}{l}\text { reluctant, } \\
\text { unactive }\end{array}$ & $\begin{array}{l}\text { veakly } \\
\text { proactive }\end{array}$ & $70 \%$ & $\begin{array}{c}\text { mostly } \\
\text { discontinuative } \\
\text { (time overlaps or } \\
\text { gaps) }\end{array}$ & $\begin{array}{l}\text { partially } \\
\text { coherent }\end{array}$ & $\begin{array}{l}\text { (partially) } \\
\text { cooperative }\end{array}$ & 3 \\
\hline 3 & $\begin{array}{l}1 \text { (C anella) } \\
2 \text { (D'Alba) } \\
3 \text { (Semerani) }\end{array}$ & silent & round & $\begin{array}{l}\text { narrow, } \\
\text { long }\end{array}$ & $\begin{array}{l}\text { around } \\
\text { the table }\end{array}$ & $\begin{array}{c}2 \rightarrow 3-2 \\
\rightarrow 1 \rightarrow 1 / 2 \\
\rightarrow 1 / 2 / 3 \rightarrow \\
1 / 2 \rightarrow 2 \rightarrow \\
1 \rightarrow 3 \rightarrow 1 \\
\rightarrow 2\end{array}$ & $\begin{array}{l}\text { attentive, } \\
\text { ready }\end{array}$ & $\begin{array}{l}\text { proactive, } \\
\text { reflexive, } \\
\text { veakly } \\
\text { reactive }\end{array}$ & $80 \%$ & $\begin{array}{c}\text { mostly } \\
\text { continuative }\end{array}$ & $\begin{array}{l}\text { partially } \\
\text { coherent }\end{array}$ & cooperative & 1 \\
\hline 4 & $\begin{array}{l}1 \text { (Aymonino) } \\
2 \text { (D'Alba) }\end{array}$ & silent & rectangular & $\begin{array}{c}\text { large } \\
\text { (n.4 paired } \\
\text { sheets) }\end{array}$ & facing & $\begin{array}{c}1 \rightarrow 1 / 2 \rightarrow \\
2 \rightarrow 1 / 2\end{array}$ & indifferent & nearly null & $90 \%$ & $\begin{array}{l}\text { (separately) } \\
\text { continuative }\end{array}$ & $\begin{array}{c}\text { In } \infty \text { herent } \\
\text { (2 drawings) }\end{array}$ & $\begin{array}{c}\text { non- } \\
\text { cooperative }\end{array}$ & 1 \\
\hline
\end{tabular}

Figure 2 Raw comparison of the main process features in different interaction sessions (Borri et al. 2006). 

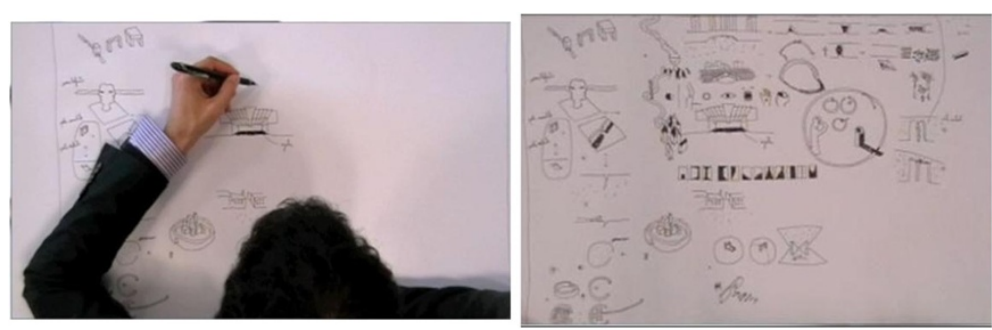

Figure 3 First meeting drawing.

The process design of the architect has been analysed through five main categories, i.e., size, form, geometry, the value of memory, logical groups. This allowed us to observe that the approach to the project, to the paper space, to the time taken to draw the various elements has gradually changed, evolving towards greater sizes of elements, as well as towards different times engaged in some areas of the sheet.

In the end, an abacus of forms and related reference memories has been set up, so as to locate each form in its conceptual development path. By dividing the work into logical groups, functional classes have been encoded toward the construction of an ontology of the design elements in designing an urban, as activated for the urban background memory of the architect.

The objective is building a tool that can help the architect have his bunch of memories constantly accumulated and constantly renewed and extended, so as to make them always available.

Through an ontology-based tool, an interactive abacus would be always open for possible amplification of the inductive abilities of the architect in his creative work.

This has suggested us to carry out an analysis of ontologies, by first looking at the aggregation and the evolution

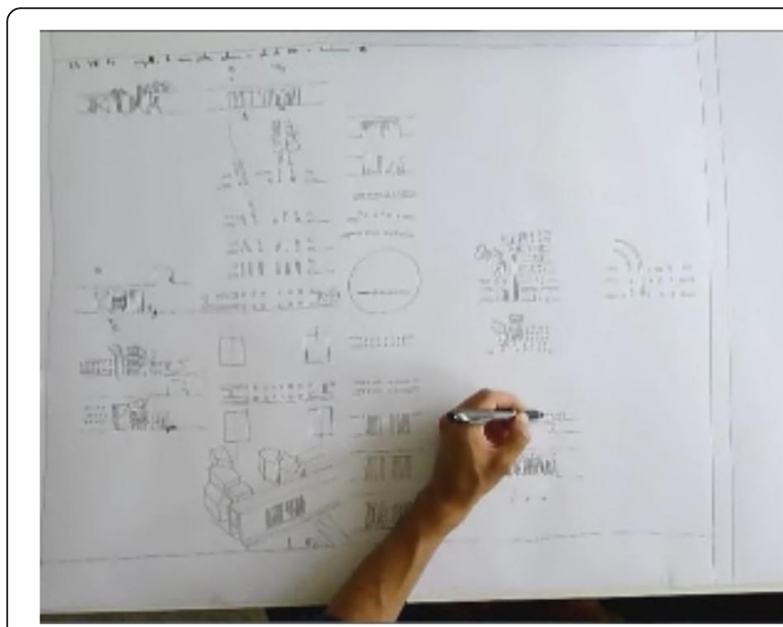

Figure 4 The final door drawing. of forms as aggregate or disaggregate entities. Then the analysis has aimed at understanding if and how space is represented with reference to primitive forms, evolving to ontologies from the first to the final drawings (Figure 5).

Currently, the study has not analysed the findings of the above ontological research. As a matter of facts, a further analysis task is planned, that will try to investigate on algorithms and functions for appropriate data processing, using MA approach. Finally, some suggestions coming from the concept of frames, used in a MA cognitive approach à la Minsky (1987), will be checked and further processed.

\section{Concluding discussions and follow up}

When dealing with urban planning and architecture, domain researches increasingly share a structural interest to the perception and cognitive representation of spaces by relevant agents. The importance of supporting space navigation and/or space organization is likewise increasing, in order to support both space users and space designers in their memory association and creativity tasks. The activity of making explorative or deliberative plans stands at the crossroads of such tasks, with manifold and intertwined facets that drive agents toward their final targets. In this

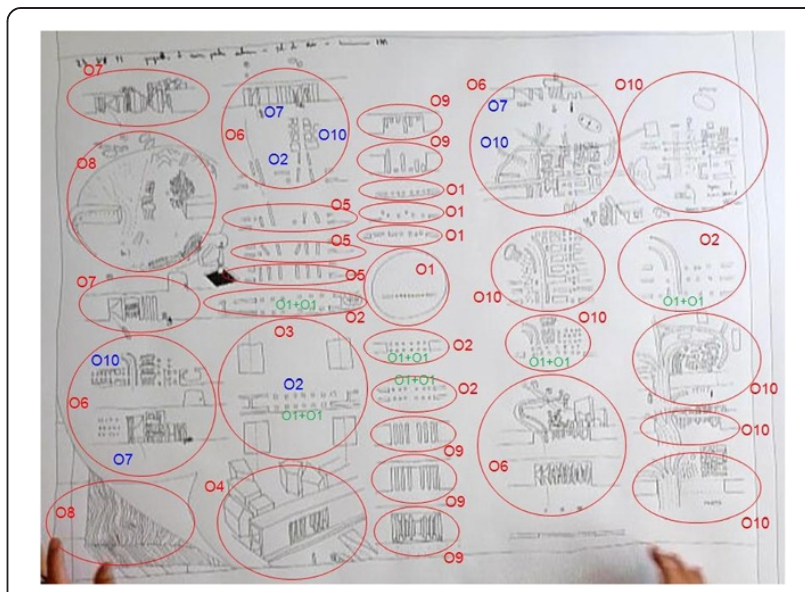

Figure 5 Ontological grouping in the last drawing. 
context, the need of models able to support space-based activities and decisions mirrors the importance of grasping concepts and relations embedded in the space ontology, so as to keep the complexity of the environmental system explored.

Different planning models can actually respond to such need, with different features and results achieved.

In the work by M.J. Schoppers, the concept of reactive plan is given a first dignity of operational activity in human agents (Schoppers 1987). Further, in the work by Herbert Simon, a form of reactive planning with no goals is conceived, embedding the possibility of a series of actions aimed at responding coherently to external stimuli. He highlights the case of chess games as a paradigmatic example of such cognitive and operational process
(Simon 1969, p.147). As a matter of facts, chess game is also cited as being an instructive case of competitive game among agents in game-theory terms (McCain 2010, p.31).

When looking at the drawings built by architects in our experimentations, their action resembles a proper competitive-game session, with the same chess-game setting à la Simon. Yet drawings are traditionally considered, similarly to many architectural works, as an actual product, i.e., resulting from a process toward a physically recognizable end. In this sense, the extent to which a drawing built by competing architects represents a no-goal plan may well appear questionable, so needing further investigation.

Contrary to Simon's positions, and more typically, plans appear as goal-oriented processes. Either in the classical cybernetic position or in more complex socially
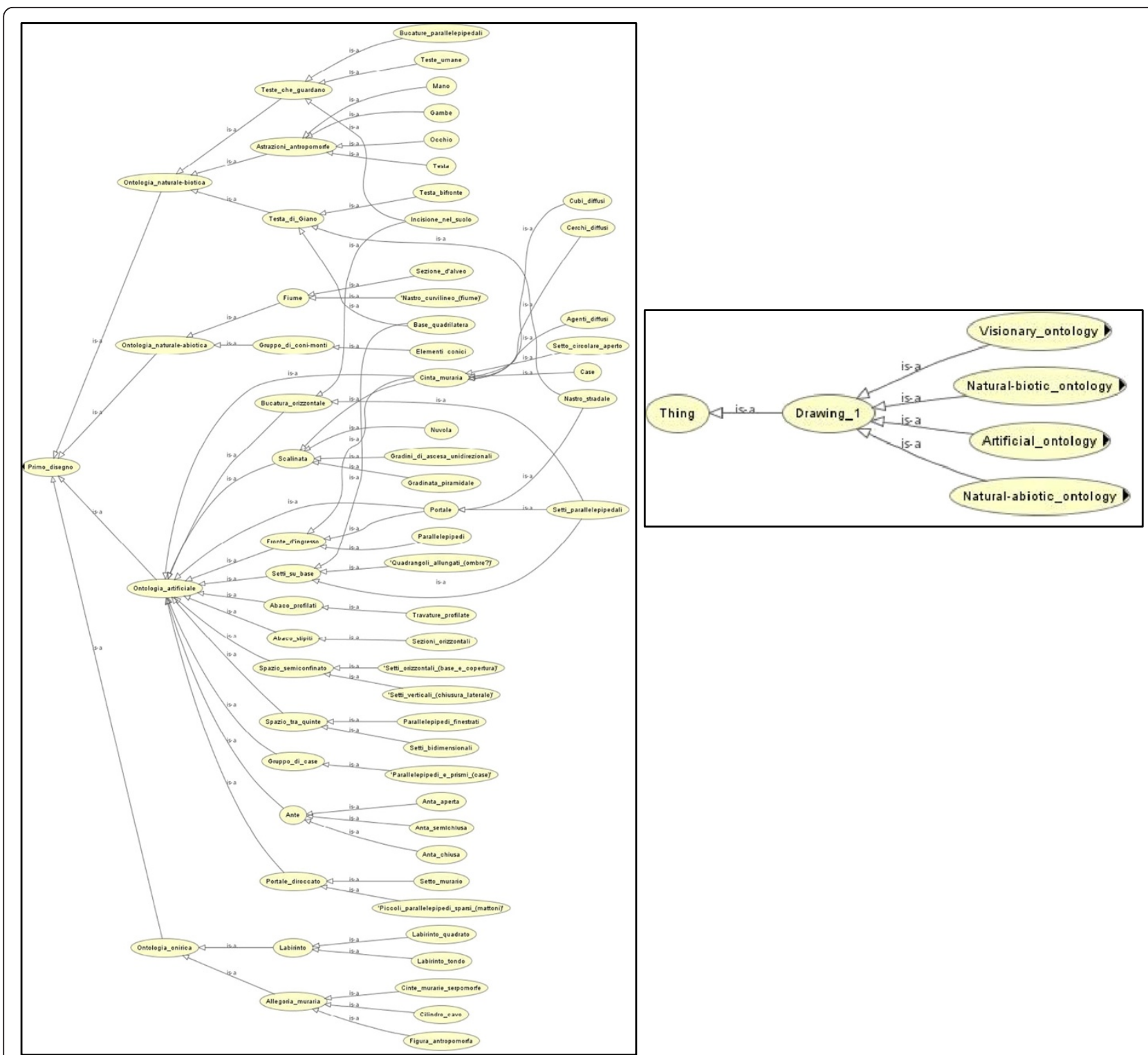

Figure 6 Ontological representation using Protégé. 
contextualized situations, a sequence of actions toward a recognizable end is largely evident in planning undertakings (Fikes and Nilsson 1971). Generally we expect architectural drawings to match such layout in most cases. Particularly self-evident appears to be the case of a single designer supporting her professional architectural activity. Yet such commonsense situations may hide activities consciously or unconsciously not oriented toward a predetermined, consistent final artwork. In that case, the extent to which an architect's drawing represents a goal-oriented plan appears questionable, so deserving further exploration.

The experimentations accounted for in this paper have been set up with such intriguing organizational framework in mind. Even if the main research questions addressed are substantially different, the model of the game layout is considered and dealt with in parallel with critical interest.

Today most of cognitive science scholars converge on conceiving creativity an ordinary specific cognition function. It is patrimony of all living agents, casually or intentionally activated in certain situations, challenging the old conception of creativity as exceptional endowment of talented cognitive agents (Bink and Marsh 2000; Ward et al. 1997; Weisberg 1993). But the idea remains of a largely unexplored set of cognitive mechanisms and abilities, hardly repeatable by computer programs. That occurs because of the evident human (biotic) features of divergence from routine reasoning and calculus, use of intuition and other intriguing biotic generic cognitive behaviours (introducing analogies, abstractions, relations, boundaries, equalities, consistencies, and beauties into the expert and domain-dependent reasoning) (Hofstadter 1995).

In this framework, we have assumed that the creativity studied in the domain of space organizing can be modelled by addressing both routine and non-routine (creative) cognitive functions. The experimentation carried out above has provided interesting results in that context.

In space organizing, creativity makes memories raise from cognitive databases and stimulate new elaborations and associations, toward the final artwork. Also, activities are often boosted in case of cooperative multi-agent tasks, even if creativity is not always separable and recognizable as a single-agent feature. Nevertheless, there is not an automatic correlation between the number of agents involved and the support to memory elicitation.

The analysis of ontologies is now being carried out by using Protégé software. The use of queries should help explaining if and how decisions on spatial drawing are dependent on a cognitive database of ontological memories (Figure 6).

However, showing how memories are a critical reference for project activities is functional in a creative perspective to produce a tool that is constant an "expansion" of personal memory. This could be further extendable with time, and elements of the architect's history and education would be always visible and available, instead of being given up by limited availability of memory allocations.

In the present introductory experimental study, creativity has emerged as a rather ordinary activity of cooperative and non-cooperative agents, whose main ability is to operate intentional associations on knowledge bases. More broadly, this preliminary study on the primitives of spatial environments seems to suggest that organizational models based on their ontological conceptualization can serve as structural layout enabling knowledge associations and supporting spatial-based decisionmaking. In this sense, it seems to confirm some basic assumptions of our work, that need to be further developed and investigated in subsequent research.

Because of such findings, the quest for models of architectural composition comes out as a reasonable target to be aimed at, in order to support and enhance planning and architectural creative efforts.

\section{Competing interests}

The authors declare that they have no competing interests.

\section{Authors' contributions}

$\mathrm{DB}, \mathrm{DC}$ and RS contributed equally to writing the article. All authors read and approved the final manuscript.

Received: 14 March 2013 Accepted: 9 October 2013

Published: 16 May 2014

\section{References}

Aboutalib S, Veloso M (2007) Towards using multiple cues for robust object recognition. Paper presented at the AAMAS '07, Honolulu, Hawaii. May 14-18

Agre PE, Chapman D (1988) What Are Plans for? Massachusetts Institute of Technology, Artificial Intelligence Laboratory, Cambridge

Arielli E (2003) Pensiero e Progettazione. La Psicologia Cognitiva Applicata al Design e all'Architettura. Bruno Mondadori, Milano

Arrow KJ (1963) Social Choice and Individual Values. Wiley, New York

Bacchus F, Kabanza F (2000) Using temporal logics to express search control knowledge for planning. Artif Intell 116:123-191

Baddeley A (1997) Human Memory: Theory and Practice. Psychology Press, Hove

Baral C, Kreinovich V, Trejo R (2000) Computational complexity of planning and approximate planning in the presence of incompleteness. Artif Intell 122:241-242

Barbanente A, Borri D, Concilio G (2001) Escapable dilemmas in planning: Decisions vs. transactions. In: Voogd H (ed) Recent Developments in Evaluation. Geopress, Groningen, pp 355-376

Bauer M, Biundo S, Dengler D, Hecking M, Koehler J, Merziger G (1991) Integrated plan generation and recognition: A logic-based approach. In: Technical Report RR-91-26. DFKI

Bink ML, Marsh RL (2000) Cognitive regularities in creative activity. Review of Gen Psychol 4(1):59-78

Blum A, Furst M (1997) Fast planning through planning graph analysis. Artif Intell 90:281-300

Borri D, Camarda D, Grassini L (2006) Distributed knowledge in environmental planning: Hybrid IT-based approaches in scenario-building contexts. Group Decision and Negotiation 6: 557-580

Borri D, Camarda D, Grassini L, Kloster K, Torregrosa ML, Vera J (2010) Planning for common goods: Cognitive frames, technology and memory in water management. In: International Conference on Organizational Learning. Knowledge and Capabilities, Boston MA. June, 3-6, 2010

Borri D, Concilio G, Selicato F, Torre C (2005) Ethical and moral reasoning and dilemmas in evaluation processes: Perspectives for intelligent agents. In: Miller D, Patassini D (ed) Beyond Benefit-Cost Analysis: Accounting for Non-Market Values in Planning Evolution. Ashgate, Brookfield, pp 249-277 Bossomaier TRJ, Green DG (2000) Complex Systems. Cambridge University Press, Cambridge 
Chang C-L, Char-Tung Lee R (1973) Symbolic Logic and Mechanical Theorem Proving. Academic Press, New York

Fikes RE, Nilsson NJ (1971) STRIPS: A new approach to the application of theorem proving to problem solving. Artif Intell 2:189-208

Finger J (1986) Exploiting Constraints in Design Synthesis. Ph.D. Thesis. Dept. of Computer Science at Stanford University, Stanford, Ca

Forsythe DE, Buchanan BG (1989) Knowledge acquisition for expert systems: Some pitfalls and suggestions. IEEE Trans Syst Man Cybern 19(3):435-442

Ginsberg ML (1989a) Ginsberg replies to Chapman and Schoppers. Al Magazine 10:61-62

Ginsberg ML (1989b) Universal planning: An (almost) universally bad idea. Al Magazine 10:40-44

Giunchiglia F, Spalazzi L (1999) Intelligent planning: A decomposition and abstraction based approach to classical planning. Artif Intell 111:329-338

Hammond KJ (1990) Case-based planning: A framework for planning from experience. Cognit Sci 14:385-443

Hofstadter DR (1995) Fluid Concepts and Creative Analogies. Basic Books, New York

Horty JF, Pollack ME (2001) Evaluating new options in the context of existing plans. Artif Intell 127:199-220

Jennings NR, Wooldridge M (ed) (1998) Agent Technology: Foundations, Applications, and Markets. Springer, Berlin

Jonsson P, Haslum P, Backstrom C (2000) Towards efficient universal planning: A randomized approach. Artif Intell 117:1-29

Kosslyn SM (1996) Image and Brain: The Resolution of the Imagery Debate. The MIT Press, Cambridge MA

Lewin K (1948) Resolving Social Conflicts. Harper and Brothers, New York

McCain RA (2010) Game Theory: A Nontechnical Introduction to the Analysis of Strategy. World Scientific Publishing, Singapore

McCarthy J (1977) Epistemological problems of artificial intelligence. In: Paper presented at the International Joint Conference on Artificial Intelligence (IJCAI77)

McCarthy J, Hayes P (1969) Some Philosophical Problems from the Standpoint of Artificial Intelligence. In: Meltzer B and Michie D (eds) Machine Intelligence 4. Edinburgh University Press, Edinburgh, pp 463-502

Mcllraith S (2000) Integrating actions and state constraints: A closed-form solution to the ramification problem (sometimes). Artif Intell 116:87-121

Minsky ML (1987) The Society of Mind. Simon \& Schuster, New York

Papadimitriou CH (1994) Computational Complexity. Addison Wesley, Reading, Ma

Rosenschein SJ (1981) Plan synthesis: A logical perspective. In: Proceedings of the 8th International Joint Conference on Artificial Intelligence. Vancouver, pp 331-337

Sandercock L (1998) Towards Cosmopolis: Planning for Multicultural Cities. Wiley, Chichester

Sawyer RK (2005) Social Emergence: Societies as Complex Systems. Cambridge University Press, Cambridge

Schön DA (1983) The Reflexive Practitioner. Basic Books, New York

Schoppers MJ (1987) Universal plans for reactive robots in unpredictable environments. Proc IJCAI-87:1039-1046

Selman B (1994) Near-optimal plans, tractability, and reactivity. In: Proceedings of the 4th International Conference on the Principles of Knowledge Representation and Reasoning (KR-94). Bonn, pp 521-529

Shepard RN (1978) Externalization of mental images and the act of creation. In: Randhawa BS, Coffman WE (ed) Visual Learning, Thinking and Communication. Academic Press, Burlington

Simon HA (1969) The Sciences of the Artificial. MIT Press, Cambridge Simon HA (1982) Models of Bounded Rationality. The MIT Press, Cambridge, MA Ward TB, Smith SM, Vaid J (ed) (1997) An Investigation of Conceptual Structures and Processes. American Psychological Association, Washington, D.C.

Weisberg RW (1993) Creativity: Beyond the Myth of Genius. W.H. Freeman \& Company, New York

Zumthor P (1998) Thinking Architecture. Zumthor and Muller Publishers, Baden

doi:10.1186/2195-2701-1-2

Cite this article as: Borri et al:: Spatial primitives and knowledge organization in planning and architecture: some experimental notes.

City, Territory and Architecture 2014 1:2.

\section{Submit your manuscript to a SpringerOpen ${ }^{\odot}$ journal and benefit from:}

- Convenient online submission

- Rigorous peer review

- Immediate publication on acceptance

- Open access: articles freely available online

- High visibility within the field

- Retaining the copyright to your article

Submit your next manuscript at $\gg$ springeropen.com 